\title{
CONSIDERAÇÕES SOBRE OS REFLEXOS DA ÉTICA EMPRESARIAL NA RESPONSABILIDADE PENAL DA PESSOA JURÍDICA
}

\section{CONSIDERATIONS ABOUT REFLECTIONS OF BUSINESS ETHICS IN THE CRIMINAL RESPONSIBILITY OF THE LEGAL ENTITY}

\author{
João Marcelo De Lima Assafim ${ }^{1}$ \\ Fábio André Guaragni ${ }^{2}$ \\ André Eduardo Detzel ${ }^{3}$
}

\section{RESUMO}

O presente trabalho analisa os reflexos da ética empresarial na responsabilização penal da pessoa jurídica pela prática de crimes ambientais. Para tanto, abordam-se algumas noções preliminares sobre a responsabilidade penal dos entes coletivos, sobretudo o fundamento jurídico constitucional e legal, além do fundamento sociológico relacionado com a sociologia do risco. Em seguida, explora-se as características e bem jurídico tutelado nos crimes ambientais. Na sequência, passa-se a estudar a ética, com ênfase na ética empresarial, principalmente no que se refere a análise dos riscos no processo de tomada de decisões no âmbito corporativo. Finalmente, tecem-se breves comentários sobre como a ética empresarial impacta no tema da incriminação dos entes coletivos.

Palavras-chave: ética, ética empresarial, responsabilidade penal da pessoa jurídica, crimes ambientais.

\footnotetext{
${ }^{1}$ Doctor en Derecho Mercantil - Universidad de Santiago de Compostela. ESPANHA, Re. Doutor em Direito Comercial Universidade de São Paulo USP, Professor Adjunto da Faculdade Nacional de Direito da UFRJ. Diretor do Programa de Mestrado em Direito da UCAM, Professor da Academia da Inovação do INPI, Professor do Doutorado em Propriedade Intelectual e Desenvolvimento do IE UFRJ / FIOCRUZ.

${ }^{2}$ Possui graduação em Direito pela Faculdade de Direito de Curitiba (1992), graduação em Administração de Empresas pela Universidade Federal do Paraná (1991), Mestrado em Direito pela Universidade Federal do Paraná (1998) e Doutorado em Direito das Relações Sociais, com ênfase em Direito Penal, pela Universidade Federal do Paraná (2002). Realizou pesquisa Pós-Doutoral na Università degli Studi di Milano (2012). Atualmente é professor titular do Centro Universitário Curitiba - UNICURITIBA, professor da Escola da Magistratura do Paraná - EMAP e professor da Fundação Escola do Ministério Público do Paraná - FEMPAR.

${ }^{3}$ Doutorando e Mestre em Direito Empresarial e Cidadania pelo Centro Universitário Curitiba - UNICURITIBA. Especialista em Direito Aplicado pela Escola da Magistratura do Paraná - EMAP. Graduado em Direito pelo Centro Universitário Curitiba - UNICURITIBA.
} 


\begin{abstract}
The present work analyzes the reflexes of the business ethics in the criminal liability of the legal person for the practice of environmental crimes. To do so, some preliminary notions about the criminal responsibility of collective entities are addressed, especially the constitutional and legal juridical foundation, in addition to the sociological foundation related to the sociology of risk. Then, the characteristics and legal assets protected in environmental crimes are explored. Then, ethics is studied, with an emphasis on business ethics, especially with regard to risk analysis in the decision-making process at the corporate level. Finally, brief comments are made on how business ethics impacts the issue of incrimination of collective entities.
\end{abstract}

KEYWORDS: ethics, business ethics, criminal liability of the legal person, environmental crimes

\title{
INTRODUÇÃO
}

É público e notório que na última década algumas das maiores empresas do Brasil estiveram envolvidas em grandes escândalos de corrupção, quem sabe os maiores de todos os tempos.

Nesse caso, restou evidenciado que as condutas contrárias ao direito e em flagrante violação a ética praticadas por essas corporações trouxeram grandes prejuízos financeiros para os cofres públicos, para a sociedade e também para as próprias empresas envolvidas.

Os recentes escândalos de corrupção revelaram que a sociedade civil está cada vez mais intolerante com as pessoas jurídicas desonestas e corruptas, sendo que a sociedade tem a sua disposição inúmeras formas de influenciar as decisões tomadas no âmbito empresarial.

Atualmente, além dos métodos tradicionais de fiscalizar e reprimir as empresas que agem em desacordo com o direito, tais como o Poder Judiciário, Administração Pública e Ministério Público, qualquer indivíduo, utilizando-se da internet ou das redes sociais, pode fazer uma denúncia, crítica ou reclamação, a qual tem a possibilidade de provocar prejuízos para as corporações.

Tais possibilidades fazem com que os entes coletivos se preocupem com a obrigação de escolher posturas éticas, ou seja, cumprir todos os compromissos e atuar de maneira honesta para com todos que mantém qualquer tipo de relação com a empresa.

Sem desconsiderar a notória influência da falta de ética nos casos de corrupção, mas no presente artigo o foco é a consequência criminal derivada do procedimento de tomada de 
decisão que não observou os critérios éticos, principalmente a hipótese de responsabilização penal da empresa.

Daí por que se mostra fundamental esclarecer em que medida eventual violação de aspectos da ética empresarial pode impactar na responsabilização penal da pessoa jurídica em virtude da ocorrência de um crime ambiental?

Por fim, é importante destacar que esse questionamento será estudado através de pesquisa predominantemente bibliográfica, bem como leitura dos textos constitucionais e legais relacionados ao tema.

\section{RESPONSABILIDADE PENAL DA PESSOA JURÍDICA NOS CRIMES AMBIENTAIS}

Apesar de ser um tema tratado há muitos anos em diversos países, a possibilidade de incriminação de empresas surgiu oficialmente no cenário brasileiro apenas com a promulgação da Constituição Federal de 1988.

Motivado pela intensa degradação ambiental ocorrida nos anos antecedentes, o legislador constituinte optou pela adoção do instituto da responsabilidade penal da pessoa jurídica, nos termos do artigo $225, \S 3^{\circ}$, da Carta Magna, o qual dispõe que "as condutas e atividades consideradas lesivas ao meio ambiente sujeitarão os infratores, pessoas físicas ou jurídicas, a sanções penais e administrativas, independentemente da obrigação de reparar os danos causados".

É importante ressaltar que até nos dias atuais o mencionado dispositivo constitucional ainda é alvo de divergências na doutrina brasileira, sobretudo quando o estudo é feito por ambientalistas ou penalistas.

O desafio inicial ocorreu no plano da hermenêutica, na medida em que os estudos foram voltados para tentar interpretar o texto do artigo $225, \S 3^{\circ}$, da Constituição da República.

De acordo com Luiz Flávio Gomes e Silvio Maciel (2011, p. 31) o texto constitucional não contempla a hipótese de responsabilidade penal pessoa jurídica. Para os mencionados autores, as empresas que degradam o meio ambiente estão sujeitas apenas às sanções administrativas.

No mesmo sentido, Miguel Reale Junior (2010, p. 344) também é partidário da ideia de que os entes coletivos não podem ser Réus em ações penais, razão pela qual argumenta que: 
$\mathrm{O}$ art. $225, \S 3^{\circ}$ da $\mathrm{CF}$ deve ser interpretado no sentido de que as pessoas físicas ou jurídicas se sujeitam respectivamente a sanções penais e administrativas. A CF estabelece que a pena não passará da pessoa do condenado (inciso XLV do art. $5 .^{\circ}$ ) e o inciso seguinte diz que a lei individualizará a pena. Portanto, há uma incapacidade penal da pessoa jurídica, que a sistemática do texto constitucional torna evidente.

A referida interpretação do texto constitucional não se mostra adequada, notadamente por permitir a conclusão de que as reprimendas penais se aplicam necessariamente as pessoas físicas, enquanto que as pessoas jurídicas estariam sujeitas somente às sanções administrativas.

Ou seja, a exegese proposta por Miguel Reale Junior está em descompasso com os princípios da proporcionalidade e da intervenção mínima, na medida em que, mesmos sendo vetores de riscos maiores, as empresas estariam sujeitas a penas mais brandas (direito administrativo) em relação àquelas aplicáveis as pessoas físicas (direito penal).

O tema relativo às sanções aplicáveis em casos de condutas ou atividades lesivas ao meio ambiente ganhou novos contornos em 1998, ano da publicação da Lei n. ${ }^{\circ}$ 9.605, ou Lei dos Crimes Ambientais.

Conforme muito bem pontuado por Rodrigo Iennaco (2010, p. 72), a Lei de Crimes Ambientais não deixou dúvida acerca da opção político-criminal do legislador de permitir a incriminação das pessoas jurídicas. Segundo Iennaco,

\footnotetext{
a referida lei previu expressamente a responsabilidade criminal da pessoa jurídica. A responsabilidade da pessoa jurídica não exclui a das pessoas físicas (co)autoras ou partícipes do mesmo fato, podendo a personalidade jurídica ser desconsiderada quando constituir obstáculo ao ressarcimento dos danos causados ao meio ambiente (Lei $9.605 / 98$, arts. $2^{\circ}$ e $\left.4^{\circ}\right) .(2010$, p. 72$)$
}

Além do aspecto ambiental, o qual será melhor analisado na sequência, a possibilidade de incriminar empresas possui fortes alicerces em aspectos sociológicos, notadamente naqueles atrelados a sociologia do risco (GUARAGNI, 2014, p.36).

Não há dúvida de que as atividades com maiores potenciais de riscos ambientais estão vinculadas de forma direta com a noção de sociedade de risco, termo este que foi criado pelo sociólogo alemão Ulrich Beck.

A obra de Beck é de grande relevância, principalmente no ponto em que altera o sentido do conceito de risco.

Para Beck (2011, p. 25-26), o risco é algo que sempre existiu, porém, no passado, além do risco ser assumido de maneira individual ele podia ser facilmente percebido através dos sentidos humanos da visão ou olfato. 
Porém, na atualidade é impossível prever os riscos através dos sentidos humanos, uma vez que as ameaças deixaram de ser individuais e passaram a ser de natureza global. (Beck, 2011, p. 26).

Ainda ao discorrer sobre os riscos, Beck (2011, p. 26) argumenta que:

\begin{abstract}
Os riscos e ameaças atuais diferenciam-se, portanto, de seus equivalentes medievais, com frequência semelhantes por fora, fundamentalmente por conta da globalidade de seu alcance (ser humano, fauna, flora) e de suas causas modernas. São riscos da modernização. São um produto de série do maquinário industrial do progresso, sendo sistematicamente agravados com o seu desenvolvimento ulterior.
\end{abstract}

$\mathrm{Na}$ era da sociedade de risco as corporações buscam e investem cada vez mais em novas tecnologias com o objetivo primordial de buscar a expansão de seus lucros.

Contudo, o traço característico dessa nova realidade é a imprevisibilidade dos riscos decorrentes das novas tecnologias, ou seja, na sociedade de risco é impossível prever os possíveis resultados nos planos econômicos, sociais e ambientais. (GUARAGNI, 2014, p. 41).

Ao estudar esse assunto, Sidney Guerra e Sérgio Guerra (2009, p. 32) pontuam que:

\begin{abstract}
$\mathrm{Na}$ sociedade atual, surge um "conflito fundamental", que promete tornar-se característico da sociedade de risco. Os progressos decorrentes da industrialização desenvolvidos até o século XIX - levavam o homem a pensar que suas ações conduziriam à segurança total, isto é, com suas técnicas o homem buscava lograr o fim dos riscos e catástrofes naturais. Contudo, o avanço tecnológico - que gerou um "risco fabricado", "fruto da decisão humana" - ocorrido durante o século passado levou o homem a sofrer os efeitos de sua própria ação.
\end{abstract}

Entretanto, verifica-se que no momento em que as empresas fizeram investimentos sem precedentes em novas tecnologias, o Estado não conseguiu acompanhar no mesmo ritmo.

Então, com o objetivo de pelo menos reduzir o risco criado pelo desenvolvimento tecnológico, sobretudo os riscos em desfavor do meio ambiente, o Estado optou pela criação da responsabilidade penal da pessoa jurídica, levando em consideração o fato de que "nas últimas décadas, a poluição, o desmatamento intensivo, a caça e a pesca predatória não são mais praticados só em pequena escala. O crime ambiental é principalmente corporativo" (MACHADO, 2012, p. 832).

Identificada a vulnerabilidade do meio ambiente em face dos riscos e perigos criados pelas novas tecnologias e pelo avanço da atividade empresarial, optou-se por eleger o bem jurídico meio ambiente como relevante penalmente.

\title{
1.1 TUTELA DO BEM JURÍDICO MEIO AMBIENTE
}


É importante relembrar que a importância do meio ambiente foi reconhecida pelo legislador constituinte, tanto é que a Constituição Federal de 1988 reservou um capítulo específico para tratar do tema.

Quando o assunto é a proteção do meio ambiente é possível invocar, de imediato, o artigo 225 da Lei Maior, que garante a todos o "direito ao meio ambiente ecologicamente equilibrado, bem de uso comum do povo e essencial à sadia qualidade de vida, impondo-se ao Poder Público e à coletividade o dever de defendê-lo e preservá-lo para as presentes e futuras gerações".

Pode-se afirmar que o referido artigo veio atender uma tendência mundial de tutela do meio ambiente. Nesse sentido, Luiz Régis Prado (2009, p. 65-66) relembra que:

\begin{abstract}
$\mathrm{Na}$ atualidade, a tutela jurídica do ambiente é uma exigência mundialmente reconhecida. A evolução normativa que se desenvolve vem determinada por um imperativo elementar de sobrevivência e de solidariedade: a responsabilidade histórica das nações pela preservação da natureza para o presente e para o futuro. Encontra-se, pois, profundamente impregnada pelos valores essenciais relativos aos direitos fundamentais, em particular o direito à vida e à saúde, geralmente consagrados nas declarações de direitos.
\end{abstract}

Todavia, é importante ressaltar que a Constituição Federal, além de contemplar a norma geral (artigo 225, caput), trouxe preceitos específicos para garantir a viabilidade de um meio ambiente ecologicamente equilibrado.

Com efeito, constata-se que o artigo $225, \S 1^{\circ}$, da Constituição da República possui sete incisos destinados ao Poder Público a fim de que este assegure a efetividade do direito ao meio ambiente ecologicamente equilibrado.

Ademais, por força da imprescindibilidade de tutelar o meio ambiente, a Constituição Federal, através do artigo $225, \S 3^{\circ}$, confirmou a hipótese de responsabilização penal de pessoas físicas e jurídicas em virtude da prática de condutas e atividades consideradas lesivas ao meio ambiente.

Diante do comando geral emanado pela Carta Constitucional, surgiu em seguida a Lei n. ${ }^{\circ}$ 9.605/1998, ou Lei dos Crimes Ambientais, diploma que versa sobre inúmeras infrações penais e respectivas sanções decorrentes de condutas lesivas ao meio ambiente.

Assim, percebe-se que a tutela do meio ambiente através da criação de tipos penais encontra fundamento jurídico na Constituição Federal e na Lei n. ${ }^{\circ}$ 9.605/1998. 


\subsection{CARACTERÍSTICAS DOS CRIMES AMBIENTAIS}

Como os ilícitos penais contra o meio ambiente são a única espécie de crimes que permitem que uma empresa seja responsabilizada penalmente, é importante tecer breves comentários sobre as características dos crimes ambientais.

Ao voltar os olhos para o ramo do Direito Ambiental, pode-se afirmar que no rol dos princípios mais relevantes estão a prevenção e precaução.

Em razão disso, quando o Direito Penal é chamado para proteger o meio ambiente, o poder punitivo estatal deve se preocupar com os riscos ambientais e não somente com os danos (MILARÉ, COSTA JUNIOR, COSTA, 2013, p. 23).

Considerando o fato de que o Direito Penal está preocupado com condutas capazes de criar riscos superiores aos permitidos, é possível classificar os crimes ambientais como sendo de perigo (MILARÉ, COSTA JUNIOR, COSTA, 2013, p. 23).

Convém relembrar, conforme lição de Gustavo Junqueira e Patrícia Vanzolini (2018, p. 250), as seguintes diferenças entre crimes de dano e de perigo:

Toma-se aqui por base a forma ou intensidade de afetação do bem jurídico. Nessa trilha: a) crimes de dano: são aqueles em que a conduta típica provoca efetiva lesão ao bem jurídico. b) crimes de perigo: são aqueles em que a conduta típica gera um risco de lesão ao bem jurídico.

Portanto, levando em conta que o Direito Penal Ambiental contempla matriz preventiva, é possível afirmar que em relação a intensidade de violação do bem jurídico os crimes ambientais podem ser classificados como crimes de perigo.

A título exemplificativo, cita-se o artigo 54 da Lei n. ${ }^{\circ}$ 9.605/1998, o qual tipifica a conduta de "causar poluição de qualquer natureza em níveis tais que resultem ou possam resultar em danos à saúde humana, ou que provoquem a mortandade de animais ou a destruição significativa da flora”.

Pois bem, a partir da simples leitura do mencionado tipo penal, percebe-se que haverá crime ambiental pelo simples fato de a poluição poder causar danos à saúde humana, ou seja, independente da presença de dano efetivo.

Também é importante ressaltar que o diploma legal que reúne a grande maioria dos tipos penais ambientais - Lei n. ${ }^{\circ}$ 9.605/1998, possui o traço de sistematização e unificação dos crimes ambientais, notadamente porque no período anterior a mencionada lei a matéria era 
tratada em inúmeras leis e diplomas normativos, situação que gerava mais insegurança do que tutela do meio ambiente (GOMES; MACIEL, 2011, p. 19).

De qualquer modo, é importante fazer a ressalva de que certos ilícitos penais ambientais são exemplos de administrativização do direito penal, isto é, "a transformação de infrações administrativas em infrações penais" (GOMES; MACIEL, 2011, p. 20).

Outra característica relevante dos crimes ambientais é que os mesmos possuem a finalidade de reparar ou pelo menos compensar o dano ambiental. Luiz Flávio Gomes e Silvio Maciel (2011, p. 23) justificam essa afirmação porque:

[...] a transação penal só é possível se for realizada prévia composição do dano ambiental (art. 27); na suspensão condicional do processo a extinção da punibilidade só pode ser decretada se ficar comprovada a reparação do dano ambiental ou a impossibilidade de realizá-la (art. 28 , I a V); as penas de prestação de serviços à comunidade, previstas para as pessoas jurídicas, estão relacionadas à reparação ou compensação do dano ambiental causado (art. 23, I a IV) etc.

Portanto, pode-se afirmar que os delitos ambientais contemplam as características de prevenção, repreensão, reparação e compensação, decorrentes de condutas ou atividades lesivas ao meio ambiente.

\section{A ÉTICA EMPRESARIAL}

De maneira preliminar a análise da ética empresarial, é importante tecer breves comentários sobre a ética, principalmente porque esse termo é frequentemente mencionado nos meios de comunicação e em diversos outros ambientes.

As questões éticas costumam ser multidisciplinares, uma vez que cruzam com diversos planos, como por exemplo: religião, economia, sociedade, meio ambiente, política, negócios, de modo que as escolhas feitas em situações éticas ultrapassam os limites do indivíduo e podem afetar terceiros (ALENCASTRO, 2010, p. 31).

Assim, diante da importância da ética, entende-se que é relevante tecer alguns comentários acerca do sentido do mencionado termo.

Apesar de ser um tema complexo, a ética é resumida por Mario Sergio Cunha Alencastro (2010, p. 33) como:

A ética é, portanto, teoria. Seja como "ciência do comportamento" ou "reflexão filosófica sobre a moral", ela tem como objeto de estudo um determinado tipo de costumes, cujas normas são interiorizadas por socialização e coletivamente aceitas numa dada sociedade. O interesse maior da ética é compreender como se dá a 
formação dos hábitos, costumes e até mesmo das regras e leis que regem uma determinada sociedade.

Não raras vezes, a palavra ética é utilizada como sinônimo de moral. Desde logo, é importante frisar que ambas possuem significado totalmente diferentes.

Sobre o tema, Aloísio Krohling (2011, p. 17) faz a ressalva que:

Os conceitos de ética e moral, ao longo da história do pensamento filosófico, vêm sendo usados quase como sinônimos, quando, na verdade, têm um significado etimológico diverso e são inteiramente diferentes a partir da filosofia. Tornou-se modismo discursar sobre ética em todos os campos do saber e em todas as profissões e até nas empresas e na política.

Ainda nessas linhas preliminares, é importante distinguir a ética da moral, uma vez que os referidos termos costumam ser utilizados indevidamente como sinônimos.

Nos termos já mencionados, tem-se que a ética trabalha em um viés teórico, "as morais correspondem às representações imaginárias que dizem aos agentes sociais o que se espera deles, quais comportamentos são bem-vindos e quais não" (SROUR, 2003, p. 31).

Em suma, enquanto ciência a ética operaria no plano teórico. Por outro lado, a moral trabalharia no plano pragmático, por meio de demonstrações empíricas.

Ao tratar da ética, também se pode afirmar que ela é contém um princípio geral, qual seja, o altruísmo.

Sobre esse particular, Robert Henry Srour (2003, p. 31) ensina que, "ser ético significa, de forma simplificada, refletir sobre as escolhas a serem feitas, importar-se com os outros, procurar fazer o bem aos semelhantes e responder por aquilo que se faz".

Assim, é inegável que a visão atual da ética é muito diferente daquela da antiguidade, sobretudo se considerarmos que os principais traços da ética na antiguidade estavam pautados na "a importância fundamental da religião, o predomínio absoluto da tradição, a absorção do indivíduo pela coletividade, e o desprezo sempre demonstrado pelos ofícios técnicos e a profissão mercantil” (COMPARATO, 2006, p. 50).

Quando se delimita o estudo da ética apenas para o ambiente empresarial, é fundamental ter em mente que o tema é relativamente novo.

Isso porque, a sociedade começou a considerar as atitudes empresariais e se preocupar com os riscos advindos delas somente com a disponibilização de produtos defeituosos no mercado norte-americano, que ocorreu na década de 1960 (ALENCASTRO, 2010, p. 59). 
Com o desgaste da imagem das empresas, bem como com a desconfiança em relação às suas ações, a discussão sobre a ética empresarial se mostra extremamente relevante, sobretudo para permitir a recuperação da confiança na empresa, auxiliar no processo de tomada de decisões e revelar que a pessoa jurídica possui responsabilidade social (CORTINA, 2005, p. 80-83).

Desde que começou a preocupação com as condutas empresariais no início da década de 1960 houve uma grande mudança paradigma.

Enquanto que no início o fundamental era sair vitorioso a qualquer custo, deixando de lado qualquer referencial ético, na atualidade está cada vez mais frequente a ideia "ter padrões éticos significa ter bons negócios e parceiros a longo prazo, pois o consumidor está cada vez mais atento ao comportamento das empresas" (ALENCASTRO, 2010, p. 61).

Contudo, é relevante destacar que os limites para o reconhecimento de uma ética empresarial partiram das próprias empresas, principalmente por defenderem ao longo de muitos anos que os negócios são pautados nas regras do mercado e em normativas próprias, sendo que a ética tradicional não teria espaço no interior da empresa (CORTINA, 2005, p. 76).

Outra ideia forte do empresariado era a de que o objetivo primordial da empresa era a obtenção de lucro, motivo pelo qual toda e qualquer ação tomada com essa finalidade não poderia ser entendida como ilegítima (CORTINA, 2005, p. 76).

Nesse sentido, Yuri Lannes (2014, p.181) frisa que "a chamada ética empresarial é, em realidade, uma ação estrategicamente mitigada, porquanto move-se de acordo com a necessidade de se manter e sobreviver em um mercado".

Não bastasse isso, as corporações defendiam que a tarefa de promover o bem-estar social era uma obrigação do Poder Público, sendo que aos entes coletivos competia respeitar as leis e as regras do mercado. (CORTINA, 2005, p. 76).

Mas, considerar uma empresa ética não se limita a analisar se a mesma respeita as leis e cumpre as regras do mercado.

Na verdade, conforme lição de Lory Tansey (apud ALENCASTRO, 2010, p. 22):

A empresa é considerada ética se cumprir com todos os compromissos éticos que tiver. Ou seja, agir de forma honesta com todos aqueles que têm algum tipo de relacionamento com ela. Estão envolvidos nesse grupo os clientes, os fornecedores, os sócios, os funcionários, o governo e a comunidade como um todo. 
A partir dessa importante contribuição é possível afirmar que uma pessoa jurídica poderá ser compreendida como ética caso aja de forma honesta para com todos aqueles que, de forma direta ou indireta, mantém com ela qualquer espécie de interação.

Porém, com a finalidade de angariar cada vez mais lucro ou obter outros tipos de vantagens, a pessoa jurídica pode acabar deixando de lado algumas obrigações éticas, circunstância que é capaz de gerar prejuízos para as pessoas que cercam ou estão inseridas na corporação, tais como fornecedores, clientes e empregados.

É importante fazer a ressalva de que o fato de a empresa buscar lucro não é algo antiético, pelo contrário, trata-se de algo imprescindível para permitir a existência de uma economiza que seja capaz de gerar a renda necessária para a subsistência das pessoas envolvidas no processo produtivo (AHRENS; SÉLLOS-KNOERR, 2013, p. 23).

Mas para que as condutas praticadas pelas empresas irradiem seus efeitos perante aqueles que a cercam, é essencial que tenha ocorrido uma prévia tomada de decisão.

Para Adela Cortina (2005, p. 51-52),

\begin{abstract}
A ética empresarial ou dos negócios, por sua vez, está centrada principalmente na concepção da empresa como uma organização econômica e como uma instituição social, ou seja, como um tipo de organização que desenvolve uma atividade peculiar, na qual são fundamentais a função diretiva e o processo de tomada de decisão. (tradução nossa).
\end{abstract}

O processo de tomada de decisões no âmbito empresarial é de fundamental importância, sobretudo porque podem atingir de forma direta ou indireta os stakeholders (SROUR, 2003, p. 50), isto é, as pessoas que mantém qualquer tipo de relação com a empresa.

Frederico Manzoni (2005, p. 16-17), tece os seguintes comentários acerca dos stakeholders:

\footnotetext{
Clientes, fornecedores, investidores, trabalhadores, demais associações de consumidores etc, não representam apenas sujeitos singulares com os quais a empresa estabelece transações. Os mesmos representam sistemas que se relacionam ao mercado e aos seus sistemas, sendo que a empresa estabelece com esses relações do tipo sistêmica, que não estão relacionadas com o administrador individual, mesmo que sejam de posição apical, e até mesmo a soma da empresa participante.
}

Devidamente esclarecida a identidade dos stakeholders, não se deve perder de vista que o exercício das funções diretivas e a tomada de decisões no âmbito corporativo geram efeitos internos e externos (SROUR, 2003, p. 50). 
Fala-se em efeitos internos na hipótese das decisões empresariais afetarem os proprietários, trabalhadores e gestores do negócio, enquanto que os efeitos externos restam configurados no momento em que a tomada de decisões atinge "clientes, fornecedores, prestadores de serviços, autoridades governamentais, bancos, credores, concorrentes, mídia, comunidade local e entidades da sociedade civil” (SROUR, 2003, p. 50).

Diante do enorme potencial de danos internos e externos a empresa, em virtude do processo de tomada de decisões, não há dúvida de que a pessoa jurídica, antes de tomar determinada decisão, deve refletir sobre os impactos da escolha de determinada alternativa e deliberar pelo caminho que esteja em harmonia com a ética empresarial.

Mas, caso a corporação selecione uma via que esteja fora das margens da ética empresarial, deverá ter em mente que a sociedade contemporânea não aceita condutas lesivas e possui mecanismos para confrontar esse tipo de ente coletivo (SROUR, 2003, p. 53).

\section{3 ÉTICA EMPRESARIAL E RESPONSABILIDADE PENAL DA PESSOA JURÍDICA}

Por fim, inicia-se a análise de eventuais reflexos da ética empresarial na responsabilidade penal da pessoa jurídica pela prática de crimes ambientais.

Oportuno relembrar que um dos requisitos dogmáticos necessários para a configuração de um crime é a culpabilidade, a qual é conceituada por Zaffaroni e Pierangeli (2008, p. 517) como sendo:

\footnotetext{
a reprovabilidade do injusto ao autor. O que lhe é reprovado? O injusto. Por que se lhe reprova? Porque não se motivou na norma. Por que se lhe reprova por não haverse motivado na norma? Porque lhe era exigível que se motivasse nela. Um injusto, isto é, uma conduta típica e antijurídica, é culpável quando é reprovável ao autor a realização desta conduta porque não se motivou na norma, sendo-lhe exigível, nas circunstâncias em que agiu, que nela se motivasse. Ao não se ter motivado na norma, quando podia e lhe era exigível que o fizesse, o autor mostra uma disposição interna contrária ao direito.
}

Em síntese, pode-se falar que o requisito da culpabilidade restará preenchido na hipótese em que o agente puder compreender a determinação da norma e determinar seu comportamento conforme tal compreensão.

Desde logo, é importante destacar que é inegável que a pessoa jurídica possui conduta, seja ela considerada autônoma ou derivada da pessoa física que age no interesse ou benefício do ente coletivo.

E a conduta da empresa, por sua vez, precisa estar dentro dos limites do direito. 
Porém, diante do dinamismo e dos constantes desafios impostos pelo mercado e pelos demais atores que cercam a pessoa jurídica, nota-se que o exercício da atividade empresarial está diretamente atrelado com o gerenciamento de riscos, através da adoção de medidas que objetivam maximizar as receitas e reduzir as despesas, a fim de obter lucro.

Nesse processo é muito comum que a corporação se depare diante de situações nas quais a escolha da melhor alternativa sob o ponto de vista econômico e financeiro não está dentro dos limites da norma.

Podem surgir situações, por exemplo, em que a pessoa jurídica esteja no impasse entre maximizar o lucro e expandir seus negócios ou respeitar direitos dos consumidores.

Quando são colocadas sobre a mesa duas ou mais possibilidade, é evidente que a empresa precisará tomar uma decisão.

E, para que a escolha assumida pelo ente coletivo seja considerada ética, todos aqueles que, de forma direta ou indireta, mantém qualquer espécie de interação com a empresa não poderão ser prejudicados.

Todavia, caso o ente coletivo decida por uma hipótese antiética, que ultrapasse os limites do risco permitido e gere um dano ao meio ambiente que tenha sido tipificado como delito na Lei n. ${ }^{\circ}$ 9.605/1998, fatalmente haverá a possibilidade de responsabilização penal da pessoa jurídica.

Nesse caso, a culpabilidade da empresa pela prática do crime ambiental, estaria fundamentada no defeito de organização ou no descumprimento da ética empresarial (DANNECKER, 2001, p. 44).

De acordo com Gerhard Dannecker (2001, p. 47):

\begin{abstract}
A capacidade de culpabilidade de uma empresa deriva de sua responsabilidade para com suas prestações coletivas defeituosas que ocorrem por conta de carências na estrutura organizativa ou na ética empresarial. O conteúdo da culpabilidade deve se referir ao injusto. Se o injusto é caracterizado por uma organização defeituosa e por uma ética empresarial insuficiente, isso deve projetar-se também na culpabilidade, que consiste em não haver criado as condições necessárias para a não realização do injusto (tradução nossa).
\end{abstract}

Ao analisar os argumentos supra de forma inversa, é possível concluir que não haverá responsabilidade penal da pessoa jurídica quando a mesma não contemplar defeito de organização e atuar conforme os padrões éticos.

Conforme pontua Pérez Arias, a teoria da culpabilidade empresarial proposta por Dannecker é relevante por trazer de forma muito clara as hipóteses exculpantes: 
DANNECKER, consciente da incapacidade de ação da pessoa jurídica (portanto não pode atuar de outro modo) encontra o fundamento da culpabilidade na reprovação sistêmica de toda a estrutura, daí que surge a possibilidade de exculpação da pessoa jurídica tão logo se constate seu correto funcionamento e, portanto, a ausência de causalidade entre o fenômeno criminoso e a organização empresarial que se evidencia correta (PÉREZ ARIAS, 2014, p. 135, tradução nossa).

Ademais, oportuno se torna dizer que apesar de os entes coletivos costumeiramente atuarem em busca de fins determinados e legítimos, em regra o lucro, não há qualquer óbice para que a pessoa jurídica sujeite essa meta submeta a premissas éticas e se organize conforme tais necessidades DANNECKER, 2001, p. 47).

Nesse ponto, abre-se o necessário paralelo para mencionar que um meio capaz de demonstrar uma cultura empresarial de fidelidade ao Direito e, consequentemente impedir o aparecimento de defeitos na organização, consiste na adoção de efetivos programas de compliance (GÓMEZ-JARA DÍEZ, 2013, p. 10).

Gómez-Jara (2013, p. 10) defende que a escolha do critério da presença ou não de programa de compliance efetivo seria o mais justo e eficaz para a incriminação ou não da pessoa jurídica, explicando que

É mais justo porque diferencia educadamente as pessoas jurídicas cumpridoras da legislação e os que não são - seria injusto considerar iguais todos os tipos de empresa, uma com um sistema de compliance efetivo, e outra que carece de qualquer compliance. E é mais eficaz porque ao permitir que as empresas evitem a responsabilidade penal mediante uma organização correta e uma cultura de cumprimento da lei, estas farão esforços significativos para programar sistemas de organização e cultura conforme as normas do Direito brasileiro (GÓMEZ-JARA DÍEZ, 2013, p. 10).

Assim, caso a empresa opte pela tomada de decisões que não guardem fidelidade ao direito ou estejam estruturadas de formas deficientes, de maneira a não observar os critérios éticos-sociais, diante de um dano ao meio ambiente o comportamento da empresa poderá ser considerado reprovável, ocasião em que o ente coletivo poderá ser incriminado.

E, mesmo que no momento da tomada da decisão a empresa não tenha tido a intenção direta de danificar o meio ambiente ou de praticar um crime, caso tais consequências tenham sido previstas como possíveis ou prováveis e a pessoa jurídica tenha assumido o risco de produzir o resultado, o ilícito penal restará configurado por força do dolo eventual.

Paulo Cesar Busato (2015, p. 420) conceitua o dolo eventual como: 
O dolo eventual, como o próprio nome indica, baseia-se na eventualidade da produção do resultado. Vale dizer: a transmissão de sentido da conduta é de que o autor projeta um resultado, que é previsto como uma hipótese possível, até mesmo, provável. No entanto, a projeção a respeito da produção do resultado não o intimida no que tange à realização da ação. [...] $\mathrm{O}$ autor não é dissuadido da atuação pela antevisão da probabilidade do resultado ruinoso.

As considerações feitas nos parágrafos anteriores reforçam as dificuldades que serão encontradas pelas pessoas jurídicas que atuam à margem da lei e de critérios éticos.

Por fim, é importante ter em mente que nos últimos anos houve uma mudança na concepção da empresa, uma vez que a noção de uma instituição que atua exclusivamente em busca do lucro foi deixada de lado, adotando-se a ideia de que os entes coletivos possuem responsabilidade com a sociedade, motivo pelo qual devem tomar decisões éticas (CORTINA, 2005, p. 81).

\section{CONSIDERAÇÕES FINAIS}

O presente artigo analisou os reflexos da ética empresarial na responsabilidade penal da pessoa jurídica nos crimes ambientas.

De forma antecedente a análise do centro do problema de pesquisa, foi necessário estudar o contexto constitucional e legal da responsabilidade penal da pessoa jurídica.

Além disso, o trabalho também precisou tecer comentários sobre os crimes ambientais, sobretudo porque tal espécie delitiva é a única na qual o ordenamento jurídico pátrio permite a incriminação de entes coletivos.

De forma prévia, optou-se pela análise do artigo 225, $\S 3^{\circ}$, da Constituição Federal e o artigo $3^{\circ}$ da Lei n. ${ }^{\circ} 9.605 / 1998$ - fundamentos legais da incriminação das empresas, os quais não deixam dúvida que a opção político-criminal adotada pelo Brasil foi a de permitir que as pessoas jurídicas figurem como rés em decorrência da prática de crimes ambientais.

Além do aspecto jurídico, verificou-se que a incriminação de entes coletivos também possui fundamentos sociológicos, merecendo destaque o fato de que era da sociedade de risco as corporações buscam e investem cada vez mais em novas tecnologias com o objetivo primordial de buscar a expansão de seus lucros.

Mas, por força da imprevisibilidade dos riscos decorrentes das novas tecnologias e do reconhecimento da vulnerabilidade do meio ambiente nesse cenário, foi preciso eleger o meio ambiente como bem jurídico penalmente relevante. 
A ética empresarial, por sua vez, ganhou espaço na discussão por sua influência no processo de tomada de decisões no âmbito das corporações, as quais eventualmente podem provocar um crime ambiental.

Conforme exposto no desenvolvimento do trabalho, a ideia basilar de que a função primordial da empresa é obter lucro a qualquer custo e que a promoção do bem-estar social é função do Estado, foi deixada de lado.

Destacou-se que, na atualidade, a sociedade busca por empresas éticas, isto é, aquelas que atuam de forma honesta para com todos aqueles que, de forma direta ou indireta, mantém com ela qualquer espécie de interação.

É importante ter em mente que além das sanções impostas pelo mercado, sobretudo de ordem econômico-financeira, caso o ente coletivo decida escolher uma opção antiética, que ultrapasse os limites do risco permitido e gere um dano ao meio ambiente que tenha sido tipificado como delito na Lei n. ${ }^{\circ}$ 9.605/1998, fatalmente haverá a possibilidade de responsabilização penal da pessoa jurídica.

Por outro lado, a possibilidade de incriminação da empresa será afastada caso a mesma não possua defeitos de organização e atue conforme os padrões éticos, sendo que um indicativo de tais fatores é a presença de efetivos programas de compliance.

Assim, pode-se concluir que a ética empresarial possui grandes reflexos na disciplina da responsabilidade penal da pessoa jurídica nos crimes ambientais, na medida em que pode ser o fundamento para a culpabilidade ou exculpação do ente coletivo

\section{REFERÊNCIAS}

AHRENS, Luis Roberto. SÉLLOS-KNOERR, Viviane Coêlho de. Segurança institucional e desenvolvimento. Curitiba: Clássica, 2013.

ALENCASTRO, Mário Sérgio Cunha. Ética empresarial na prática: liderança, gestão e responsabilidade corporativa. Curitiba: Editora IBPEX, 2010.

BANDEIRA, Gonçalo S. de Melo. A RESPONSABILIDADE DAS EMPRESAS PELO CRIME DE CORRUPÇÃO: O CASO PORTUGUÊS A PARTIR DE UMA PERSPECTIVA DE DIREITO PENAL, MAS TAMBÉM DE CRIMINOLOGIA. Revista Juridica, [S.1.], v. 4, n. 37, p. 61-96, nov. 2015. ISSN 2316-753X. Disponível em: <http://revista.unicuritiba.edu.br/index.php/RevJur/article/view/1042/729>. Acesso em: 21 abr. 2020. doi:http://dx.doi.org/10.21902/revistajur.2316-753X.v4i37.1042.

BECK, Ulrich. Sociedade de risco: rumo a uma outra modernidade. Traduzido por Sebastião Nascimento. São Paulo: Editora 34, 2011. 
BUSATO, Paulo César. Direito Penal: parte geral. 2. ed. São Paulo: Atlas, 2015.

COMPARATO, Fabio Konder. Ética: direito, mora e religião no mundo moderno. 2. ed. São Paulo: Companhia das Letras, 2006.

CORTINA, Adela. Ética de la empresa: claves para una nuova cultura empresarial. Madrid: Trotta, 2005.

DANNECKER, Gerhard. Reflexiones sobre la responsabilidad penal de las personas jurídicas. Revista Penal, Salamanca, n. 7, p. 40-54, 2001. Disponível em: < http://www.uhu.es/revistapenal/index.php/penal/article/view/97/92> Acesso em: 25 de maio de 2016.

GOMES, Luiz Flávio; MACIEL, Silvio. Crimes ambientais: comentários à lei 9.605/98. São Paulo: Editora Revista dos Tribunais, 2011.

GÓMEZ-JARA DÍEZ, Carlos. A responsabilidade penal da pessoa jurídica e o dano ambiental. Porto Alegre: Livraria do Advogado, 2013.

GUARAGNI, Fábio André. Responsabilidade penal da pessoa jurídica e a proteção ao meio ambiente. In: CHOUKR, Fauzi Hassan; LOUREIRO, Maria Fernanda; VERVAELE, John (Org.). Aspectos contemporâneos da responsabilidade penal da pessoa jurídica. v. 2. São Paulo: Federação do Comércio de Bens, Serviços e Turismo do Estado de São Paulo, 2014.

GUERRA, Sidney; GUERRA, Sérgio. Curso de direito ambiental. Belo Horizonte: Fórum, 2009.

IENNACO, Rodrigo. Responsabilidade penal da pessoa jurídica. 2. ed. Curitiba: Juruá, 2010.

JUNQUEIRA, Gustavo; VANZOLINI, Patrícia. Manual de direito penal: parte geral. 4. ed. São Paulo: Saraiva, 2018.

KROHLING, Aloísio. A ética da alteridade e da responsabilidade. Curitiba: Juruá, 2011.

LANNES, Yuri Nathan da Costa. Ética empresarial e função social. Revista Jurídica, Curitiba, v. 3, n. 36, p. 177-193. 2014.

MACHADO, Paulo Affonso Leme. Direito ambiental brasileiro. 20. ed. rev., atual. e ampl. São Paulo: Malheiros Editores, 2012.

MANZONI, Frederico. La responsabilità sociale dell'impresa: analisi del fondamento etico. In: MONESI, Carlo (Coord.). I modelli organizzativi ex d.lgs. 231/2001: ética d'impresa e punibilità degli enti. Milano: Giuffrè Editore, 2005.

MILARÉ, Édis; COSTA JUNIOR, Paulo José da; COSTA, Fernando José da. Direito Penal Ambiental. 2. ed. rev., atual. e ampl. São Paulo: Editora Revista dos Tribunais, 2013.

PÉREZ ARIAS, Jacinto. Sistema de atribuición de responsabilidad penal a las personas jurídicas. Madrid: Dykinson, 2014. 
PRADO, Luiz Régis. Direito penal do ambiente. 2. ed. rev., atual. e ampl. São Paulo: Editora Revista dos Tribunais, 2009.

REALE JUNIOR, Miguel. A responsabilidade penal da pessoa jurídica. In: PRADO, Luiz Régis; DOTTI, René Ariel (Coord.). Responsabilidade penal da pessoa jurídica: em defesa do princípio da imputação penal subjetiva. 2. ed. rev., atual. e ampl. São Paulo: Editora Revista dos Tribunais, 2010.

SROUR, Robert Henry. Ética empresarial: a gestão da reputação. 2. ed. rev. e atual. Rio de Janeiro: Campus, 2003.

ZAFFARONI, Eugenio Raúl; PIERANGELI, José Henrique. Manual de direito penal brasileiro: parte geral. v.1. 7 ed. rev. e atual. São Paulo: Revista dos Tribunais, 2008. 